\title{
Community Attitudes Towards People with Down's Syndrome: A Sample From Iraq
}

\author{
Sadeer G. Al-Kindi ${ }^{1, *}$, Taha Al-Juhais hi ${ }^{1}$, Atheer J. Al-Saffar ${ }^{2}$ \\ ${ }^{1}$ Weill Cornell Medical College, P.O Box 24144, Doha, Qatar \\ ${ }^{2}$ Department of Community and Family Medicine, College of Medicine, Al-Nahrain University, Baghdad, Iraq
}

\begin{abstract}
Down syndrome (DS) is one of the most common congenital disorders associated with intellectual disability and social stigma. Co mmunity attitudes and knowledge of this condition are important for inclusion of people with DS into the community and improving their quality of lives. Results from surveys from the world showed that people still hold negative attitudes towards inclusion of people with DS. Studies in the Arab world are sparse and there are no data exp loring these attitudes in Iraq in the absence of formal awareness programs; hence, this study was done to report and analyse the Iraqi community attitudes towards people with Down syndrome. A survey questionnaire of the attitudes from a sample from the community was done. Results showed that Iraqis still hold negative thoughts towards inclusion of people with DS, however they are less negative than their counterparts in Europe and United States. Female gender was the most common factor associated with positive attitudes. The results of this study underscore the importance for organized campaigns and programs to increase awareness towards DS and inclusion in the community. Further research is required to explore the factors underlying these attitudes.
\end{abstract}

Keywords Down Syndrome, Public Attitudes, Inclusion, Iraq

\section{Introduction}

Down's syndrome (DS) is a chromosomal disorder that results in intellectual disability and growth problems[1]. Worldwide incidence of this syndrome is 1 in 1000 births and increases exponentially with the maternal age. People with DS usually have reduced life expectancy and suffer from mental retardation, heart problems, Alzheimer's disease among other complications. However, the severity of the disease differs from patient to patient[2].

Perceptions of the disease and the public attitudes towards people with Down syndrome are very important in the inclusion of these people in the community and the supporting families[3], and early interventions can improve their quality of lives[4].

Several surveys have been carried out to explore the understanding and the attitudes of people towards people with DS and their inclusion in the community. However, most of these studies focus on specific groups of people (e.g. students [5], teachers [6], and physicians [7]).

Other studies that included different groups of people has found that United States communities still hold negative opinions towards people with DS[8]. Another study found that European communities also still hold negative attitudes towards people with Down's syndrome[9].

* Corresponding author:

saa2025@qatar-m ed.cornell.edu (Sadeer Al-Kindi)

Published online at http://journal.sapub.org/phr

Copyright (C) 2012 Scientific \& Academic Publishing. All Rights Reserved
Studies of community attitudes in the Arab world are lacking. One Lebanese study reported that there is a positive attitude towards inclusion by the parents of children with DS in 2 private schools in Lebanon[10].

Iraq is a country in the Middle East with an estimated population of $31,234,000$ [11]. There are no official statistics about Down's syndrome in Iraq and no studies exploring the attitudes towards disability. Children with mental disabilities are not enrolled in public schools and nurseries in Iraq.

Formal awareness programs about intellectual disability are lacking in Iraq. The awareness and support for children with DS is mainly from non-governmental organizations. One such organization is the Iraqi Down Syndrome Association which endows an educational centre for children with DS named "HibatoAlla Centre" which involves a kindergarten and primary school. This institute was established in 1993 with individual efforts. It now provides educational opportunities for over 100 children with DS. The Down syndrome association also holds annual conferences and some other activities to increase awareness towards DS[12].

The objective of th is study is to elicit the self-reported attitudes of people from the Iraqi community towards children with DS. The results will provide better understanding of the public awareness towards DS and underscores the need for formal and organized programs for support and awareness.

The results of a website-based survey are presented and analysed to assess the attitudes towards the inclusion of people with Down's syndrome and some of the factors that 
are associated with these attitudes.

\section{Methods}

A cross-sectional study was conducted using a self-admin istered questionnaire to measure the public response towards inclusion of people with Down's syndrome in the community, public schools, and individual relationships. The questionnaire consisted of 2 parts: the first part is concerned with the demographics (i.e. gender, age, marital status, and education level), the previous experience with people with Down's syndrome and whether the responders had a family member with Down's syndrome. The second part consisted of six questions which were designed to measure 3 aspects of personal opinions and attitudes towards inclusion of people with Down's syndrome. These were from educational, community, and personal perspectives. Some questions were adapted from previous surveys $[8,9]$.

The six questions used in the survey are as follows:

$\rightarrow$ Question 1: Do you think people with DS need special schools?

$\rightarrow$ Question 2: Do you think mixing students with DS in public schools affects other students?

$\rightarrow$ Question 3: Do you support offering jobs to people with DS?

$\rightarrow$ Question 4: Do you think people with DS can be integrated into the community?

$\rightarrow$ Question 5: If you were a teacher, would you be able to teach people with DS?

$\rightarrow$ Question 6: Can you be a friend with anyone with DS?

An electronic survey website (www.kwiksurveys.com) was used for data collection. The recruitment process was done using the social network website (Facebook). Recruitment messages were sent to members of Facebook groups and fan pages that likely to include Iraqis. The questionnaire included a question asking the responders whether they identify themselves as "Iraqi" or not. The duration of data collection was between June 2011 and August 2011.

Data fro $m$ the survey were ana lysed using Microsoft Excel and Statistical Package for the Social Sciences SPSS 18.0 (SPSS Inc., Chicago, Ill). Categorical variables were described using frequency distribution and percentages. Chi square test was used to examine the association between the different factors with outcome. P-value of less than 0.05 was considered as statistically significant.

\section{Results}

A total of 878 responses were received. Four hundred eighty three respondents (55\%) were males, $657(74.8 \%)$ are single, and $187(80.5 \%)$ of those who were married had kids. Five hundred sixty five respondents $(64.4 \%)$ between 21 and 31 years old, and their education level was mostly undergraduate degree constituting $63.4 \%$. Of those, $528(60.1 \%)$ reported that they had previous encounters with people with Down's syndrome, while only $94(10.7 \%)$ had people with
Down's syndrome in their families (Table 1).

Regarding the inclusion-in-education perspective, $80.3 \%$ of the respondents think that people with DS need special schools ( $83 \%$ of the males and $77 \%$ of the females), and $70.5 \%$ think that mixing students with DS in public school will negatively affect other students academically ( $76 \%$ of the males, and $64 \%$ of the females). From the community inclusion perspective, $89.4 \%$ support offering jobs to people with DS ( $87 \%$ of the males, and $94 \%$ of the females), and $84.5 \%$ think that people with DS can be integrated into the community ( $81 \%$ of the males, and $89 \%$ of the females). On the personal field, $78.5 \%$ of the respondents think that they can be friends with people with DS (73\% of the males, and $84 \%$ of the females), and $76.7 \%$ think that they can teach students with DS, if they were teachers $(75 \%$ of the males and $83 \%$ of the females), see Figure (1).

Older respondents were significantly more capable to be friends with anyone with Down's syndrome than younger ones $(P=0.044)$. There is a significant association between the gender of the respondent and all the questions asked regarding Down's syndrome. For all questions females were more convinced than males regarding inclusion of people with DS in their community except for the opinion that children with DS need special schools and mixing students with DS in public schools with other students where males had more positive responses ( $p$ values are shown in Table 2).

Table 1. Distribution of respondents according to their demographic characteristics

\begin{tabular}{lcc}
\hline Variable & & Frequency (\%) \\
\hline Age groups (Ye ars) & $<21$ & $143(16.3 \%)$ \\
& $21-31$ & $565(64.4 \%)$ \\
Gen der & $>31$ & $170(19.4 \%)$ \\
& Male & $483(55.0 \%)$ \\
Marital Status & Female & $395(45.0 \%)$ \\
Have Chil dren & Married & $221(25.2 \%)$ \\
& Single & $657(74.8 \%)$ \\
Edu cational & Yes & $43(19.5 \%)$ \\
Qualification & No & $178(80.5 \%)$ \\
Fre vious encoun ter & High school or less & $226(25.7 \%)$ \\
with people with DS? & Bachelor & $557(557 \%)$ \\
DS? & Yes & $95(10.8 \%)$ \\
\hline
\end{tabular}

Married respondents agreed that people with DS can be mixed with the community more than single respondents $(p=0.009)$, but those who did not have child ren reported the lack of ability to teach children with DS $(\mathrm{p}=0.02)$.

\section{Discussion}


The results of this survey show that Iraqis still hold some negative attitudes towards people with disabilities. This is especially true with regards to inclusion in education where most of the respondents supported putting students with DS in special schools $(80.3 \%)$ and that mixing them would a ffect their colleagues in school $(70.5 \%)$. From a cultural perspective, respondents might prefer placing students with DS in special schools to protect them from violence and that those people are better in a special environment to facilitate their learning experience. An American study, found that only $30 \%$ supported special schooling for people with DS[8], and a full $100 \%$ of children with DS were enrolled in the public school system in Rome, Italy[13] compared to results of the present study that show far more support for separation. This finding is in light of the system in the Iraqi public schools where children with mental disabilities are not enrolled with other students.

Respondents had more positive attitudes with community-inclusion of people with DS. Most of the respondents supported offering jobs $(89.4 \%)$ and integrating them in the community in general $(84.5 \%)$. In comparison with the American study, our results showed that Iraqis had more positive attitudes towards people with DS's ability to work than Americans (65.7\%)[8].

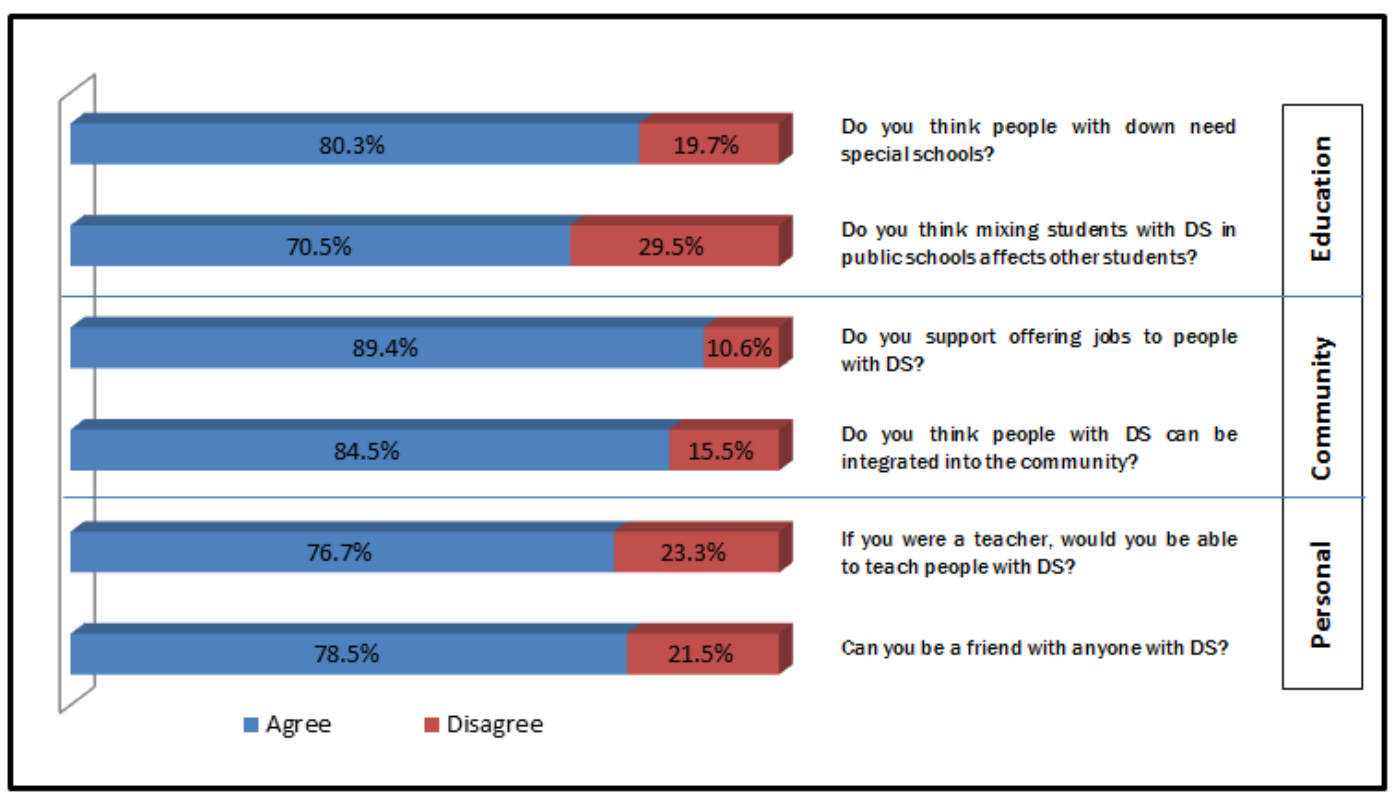

Figure 1. Responses from the self-administered questionnaire

Table 2. Distribution of respondents according to their responses to the six questions (significant results are in bold)

\begin{tabular}{|c|c|c|c|c|c|c|c|}
\hline Parameter & & Q1 (\% yes) & Q2 (\% yes) & Q3 (\% yes) & Q4 (\% yes) & Q5 (\% yes) & Q6 (\% yes) \\
\hline \multirow{4}{*}{ Age } & $<21$ & 76.9 & 67.1 & 87.4 & 81.8 & 77.3 & 74.8 \\
\hline & $21-31$ & 80.9 & 74.1 & 89.7 & 83.9 & 74.4 & 77.3 \\
\hline & $>31$ & 81.2 & 70.3 & 91.7 & 88.8 & 78.4 & 85.3 \\
\hline & Significance & $\mathrm{P}=0.54$ & $\mathrm{P}=0.39$ & $\mathrm{P}=0.46$ & $\mathrm{P}=0.19$ & $\mathrm{P}=0.56$ & $P=0.044$ \\
\hline \multirow{3}{*}{ Gender } & Male & 83.0 & 76.0 & 86.5 & 81.0 & 72.5 & 74.5 \\
\hline & Female & 77.0 & 63.8 & 93.6 & 88.9 & 83.5 & 83.3 \\
\hline & Significance & $P=0.03$ & $P=0.00001$ & $P=0.001$ & $P=0.001$ & $P=0.00001$ & $P=0.002$ \\
\hline \multirow{3}{*}{ Marital Status } & Single & 80.5 & 70.6 & 89.6 & 82.6 & 77.5 & 77.2 \\
\hline & Married & 79.6 & 70.1 & 90.0 & 90.0 & 77.4 & 82.4 \\
\hline & Significance & $\mathrm{P}=0.78$ & $\mathrm{P}=0.89$ & $\mathrm{P}=0.85$ & $P=0.009$ & $\mathrm{P}=0.99$ & $\mathrm{P}=0.11$ \\
\hline \multirow{3}{*}{ Having Children } & No & 79.1 & 69.8 & 90.7 & 93.0 & 90.7 & 90.7 \\
\hline & Yes & 79.8 & 70.2 & 89.9 & 89.3 & 74.1 & 80.3 \\
\hline & Significance & 0.92 & 0.95 & 1.00 (F.E.) & 0.58 (F.E.) & 0.02 & 0.11 \\
\hline \multirow{4}{*}{ Educational level } & High school or less & 78.8 & 69.9 & 89.8 & 85.4 & 77.9 & 80.1 \\
\hline & Bachelor degree & 79.5 & 70.4 & 89.7 & 84.6 & 74.2 & 79.0 \\
\hline & Postgraduat es & 88.4 & 72.6 & 89.5 & 82.1 & 77.8 & 71.6 \\
\hline & Significance & $\mathrm{P}=0.11$ & $\mathrm{P}=0.88$ & $\mathrm{P}=0.996$ & $\mathrm{P}=0.76$ & $\mathrm{P}=0.73$ & $\mathrm{P}=0.21$ \\
\hline \multirow{3}{*}{ Previous Encounter } & No & 80.6 & 68.3 & 91.7 & 82.6 & 77.9 & 77.1 \\
\hline & Yes & 80.1 & 72.0 & 88.4 & 85.8 & 77.2 & 79.4 \\
\hline & Significance & $\mathrm{P}=0.87$ & $\mathrm{P}=0.24$ & $\mathrm{P}=0.12$ & $\mathrm{P}=0.196$ & $\mathrm{P}=0.81$ & $\mathrm{P}=0.44$ \\
\hline \multirow{3}{*}{ DS in the family } & No & 80.7 & 70.9 & 89.9 & 84.2 & 77.4 & 78.1 \\
\hline & Yes & 76.6 & 67.0 & 88.3 & 87.2 & 77.4 & 81.9 \\
\hline & Significance & $\mathrm{P}=0.34$ & $\mathrm{P}=0.434$ & $\mathrm{P}=0.63$ & $\mathrm{P}=0.44$ & $\mathrm{P}=0.995$ & $\mathrm{P}=0.39$ \\
\hline
\end{tabular}


With respect to the attitudes to the personal attitudes of the respondents, responses were mostly positive towards relationships with people with DS. Most respondents $(76.7 \%)$ were able to teach people with DS compared to $(69.7 \%)$ of the Americans who were willing to work with a student with DS on a clas s project. Most of our respondents were a ls o able to be friends with people with DS (78.5\%) in comparison with $(57.5 \%)$ in the A merican study [8].

One of the factors affecting these attitudes was the female gender. Significantly fewer females supported special schooling and separation, while significantly more females supported offering jobs, mixing them in the community, had the ability to teach students with DS, and be friends with them. These findings agrees with other studies proving that female gender is a defining factor in attitudes towards people with intellectual challenges [8,9].

Older people $(>31)$ reported ability to be friends with people with DS significantly more than younger age groups, and married people held mo re positive attitudes towards their integration into the community probably because of their more life experiences and responsibility feelings towards such conditions. However, and interestingly, people with children reported less ability to teach students with DS.

This study has several limitations. The respondents were not randomly selected, likely to be literate, speaking English language, have access to the internet and use the social networking website used in this study and thus may not necessarily represent the population Also, respondents were likely to be interested in the topic believing that answering the questionnaire will help in policy making and hence may show falsely positive results.

The objectives of this study were to explore the attitudes of Iraqis towards people with DS as a model of intellectual disability. The cultural and religious similarity may allow extrapolating these results to all countries in the Middle East. The importance of the results may help in policy-making and initiation of awareness programs towards supporting the intellectually disabled and prioritizing basic self-help skills for them in order to elevate the burden on their families.

The lack of formal awareness and support programs along with the results of this survey underscore the urgent need for organized campaigns and programs to publicize issues of people with DS and allow better integration into the community.

Further research to explore the attitudes in more realistic approach is warranted. This may lead to better understand the factors contributing to these attitudes within this culture.

\section{ACKNOWLEDGEMENTS}

We would like to sincerely thank Mrs. Shaira Abdulateef Mustafa, chairman of Iraqi Down Syndrome As sociation and the headmistress of the HibatoAlla Centre for special edu- cation for her extraord inary efforts to support children with Down syndrome in Iraq and for providing us with some information about Down syndrome in Iraq.

\section{REFERENCES}

[1] Liptak Gregory S. "Down Syndrome (Trisomy 21; Trisomy G)". Merck Manual. (December 2008). Retrieved 2012-2-1. "Symptoms"

[2] Weijerman ME, de Winter JP. Clinical practice. The care of children with Down syndrome. Eur J Pediatr. 2010 Dec;169(12):1445-52.

[3] Antonak RF, and Livneh H. Measurement of attitudes towards persons with disabilities. Disabil Rehabil. 2000 Mar 20;22(5):211-24.

[4] Bailey DB, Bruder MB, Hebbler K, Carta J, Defosset M, Greenwood C, Kahn L, Malli S, Markowitz J, Spiker D, Walker D, Barton L. Recommended outcomes for families of young children with disabilities. Journal of Early Intervention. 2006;28:227-251.

[5] Townsend MA, Wilton KM, Vakilirad T. Children's attitudes toward peers with intellectual disability. J Intellect Disabil Res. 1993 Aug;37 ( Pt 4):405-11.

[6] Gilmore L, Campbell J, Cuskelly M. Developmental expectations, personality stereotypes, and attitudes towards inclusive education: Community and teacher views of Down syndrome. International Journal of Disability, Development and Education. 2003;50 (1):65-76.

[7] Haslam RH, and Milner R. The physician and Down syndrome: are attitudes changing? J Child Neurol. 1992 Jul;7(3):304-10

[8] Pace JE, Shin M, Rasmussen SA. Understanding attitudes toward people with Down syndrome. Am J Med Genet A. 2010 Sep;152A(9):2185-92.

[9] Gash H, Gonzales SG, Pires M, Rault C. Attitudes toward Down syndrome: A national comparative study: France, Ireland, Portugal, and Spain. Irish J Psychol 2000; 21: 203-214.

[10] ElZein HL. Attitudes toward inclusion of children with special needs in regular schools (A case study from parents' perspective). Ed Res and Rev 2009. Apr 4(4):164-172.

[11] "CIA - The World Factbook". Cia.gov. Retrieved 2012-2-01.

[12] Mustafa/Mansour SAL. Developing education and health services for Iraqi children with Down syndrome. Down Syndrome News and Update. 2006; 5(2);75-77.

[13] Bertoli M, Biasini G, Calign ano M T, . Celani G, De Grossi G, Digilio M C, Fermariello C C, Loffredo G, Luchino F, Marchese A, Mazotti S, Menghi B, Razzano C, Tiano C Tiano, Zambon Hobart A, Zampino G, Zuccalà G.Needs and challenges of daily life for people with Down syndrome residing in the city of Rome, Italy. J of Intellectual Disability Research 2011; 55(8): 801-20. 